\title{
Easy-to-Implement Integral Numerical Simulation of Multi-phase Drives under Fault Supply Condition
}

\author{
X. Kestelyn, F. Locment, Y. Crévits and E. Semail \\ L2EP ENSAM, 8 Bd Louis XIV, 59046 Lille France \\ xavier.kestelyn@lille.ensam.fr
}

\begin{abstract}
This paper presents an easy way to model multiphase electrical drives in fault supply conditions. The presented technique makes it possible to simulate the drive in various configurations with keeping the same integral model established in normal mode. Simulations of a seven-leg seven-phase drive are carried out and compared to experimental measurements.
\end{abstract}

\section{INTRODUCTION}

More and more electrical systems need a high level of reliability. Among the potential solutions, multi-phase machines take a particular place to improve the reliability of $\mathrm{AC}$ drives [1]. Efficient current controls lead to the use of the multiple $d q$ spaces concept [2]-[3]. As for three-phase case, this control mode needs to transform the real electrical variables expressed into a stationary reference frame into fictitious variables expressed into multiple one or twodimensional $d q$ rotating reference frames. For a n-phase machine, the first harmonics of electrical variables can be regarded as DC components and the use of PI controllers in the current loops leads to null steady state errors [11].

When one or several phases are short or open-circuited, ripples appearing in the $d q$ currents require a particular attention. Many authors have proposed a new model of the machine taking into account these asymmetrical connections [4]-[5]. These models have made it possible to deduce efficient current controls. However, a new model is built for each new case. For machines with a high number of phases, this technique becomes rapidly cumbersome and time consuming. Moreover, some authors use the derivative operation to model voltages across open-circuited phases which can lead to problems of convergence, stability and long simulation time when using numerical simulations [7].

This paper proposes a simple and easy-to-implement way of integral modeling which makes it possible to achieve numerical simulations of multi-phase drives under fault conditions with keeping the original model of the drive.

\section{MULTI-PHASE DRIVE MODELLING IN NORMAL MODE}

Under the assumptions of balanced phases, linear magnetic behavior, no eddy currents and slots phenomenon, the electrical behavior of a n-phase machine can be modeled using (1):

$$
\overrightarrow{v_{a b c}}=\Re \overrightarrow{i_{a b c}}+\frac{d \overrightarrow{\lambda_{a b c}}}{d t}
$$

with $\overrightarrow{v_{a b c}}, \overrightarrow{i_{a b c}}, \overrightarrow{\lambda_{a b c}}$ stator voltage, current and flux vectors with real variables as coordinates and $\mathfrak{R}$ a $n-b y-n$ diagonal stator resistance matrix.

Using the multiple $d q$ spaces concept [3]-[11], a vector $\overrightarrow{x_{a b c}}$ is transformed into a vector $\overrightarrow{x_{d q}}$ using a transformation $T_{a b c-d q}$ from $a b c$ to $d q$ references frames.

$$
\overrightarrow{x_{d q}}=T_{a b c-d q}\left(\overrightarrow{x_{d q}}\right)
$$

Equation (1) can then be rewritten as:

$$
\overrightarrow{v_{d q}}=\Re \overrightarrow{i_{d q}}+\frac{d \overrightarrow{\lambda_{d q}}}{d t}
$$

with $\overrightarrow{v_{d q}}, \overrightarrow{i_{d q}}, \overrightarrow{\lambda_{d q}}$ stator voltage, current and flux vectors with $d q$ variables as coordinates.

In (3), the flux vector can be broken down into two components due to the stator currents and the rotor effect:

$$
\overrightarrow{\lambda_{d q}}=\overrightarrow{\lambda_{d q s}}+\overrightarrow{\lambda_{d q r}}
$$

Transformation $T_{a b c-d q}$ is then chosen in the way that $\overrightarrow{\lambda_{d q s}}$ depends to $\overrightarrow{i_{d q}}$ by a diagonal stator inductance matrix $\ell_{d q}$. This choice leads to magnetically two-dimensional independent systems and makes it possible to achieve efficient and simple current controls.

Using the electromotive force vector (emf) $\overrightarrow{e_{d q}}=\frac{d \overrightarrow{\lambda_{d q r}}}{d t}$, (3) becomes for the $j^{\text {th }}$ two-dimensional $d q$ space $\left(j \leq \frac{n}{2}+1\right)$ :

$$
\overrightarrow{v_{d q j}}=\Re \overrightarrow{i_{d q j}}+L_{d q j} \frac{d \overrightarrow{i_{d q j}}}{d t}+\overrightarrow{e_{d q j}}
$$

with $L_{d q j}$ the $d q$ self inductance of the $j^{\text {th }} d q$ system.

As (5) models a symmetrical two-phase machine, the nphase machine can then be considered as equivalent to a set of $\frac{n}{2}+1$ two-phase fictitious machines (for $n$ odd).

Machine torque $T$ is then obtained by summing each torque $T_{j}$ provided by each two-phase fictitious machine: 


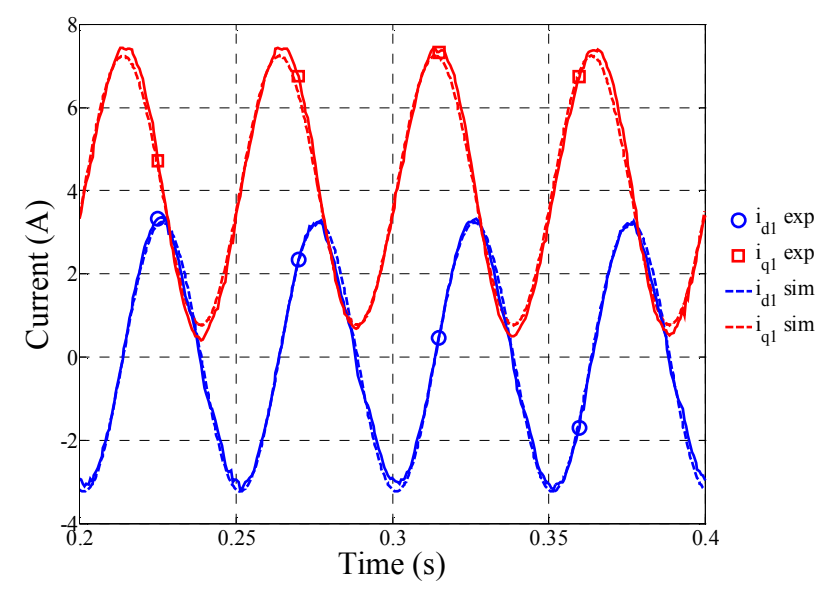

Fig. 8. Experimental and Simulated $M_{l} d q$ currents in the case of three open-circuited phases.

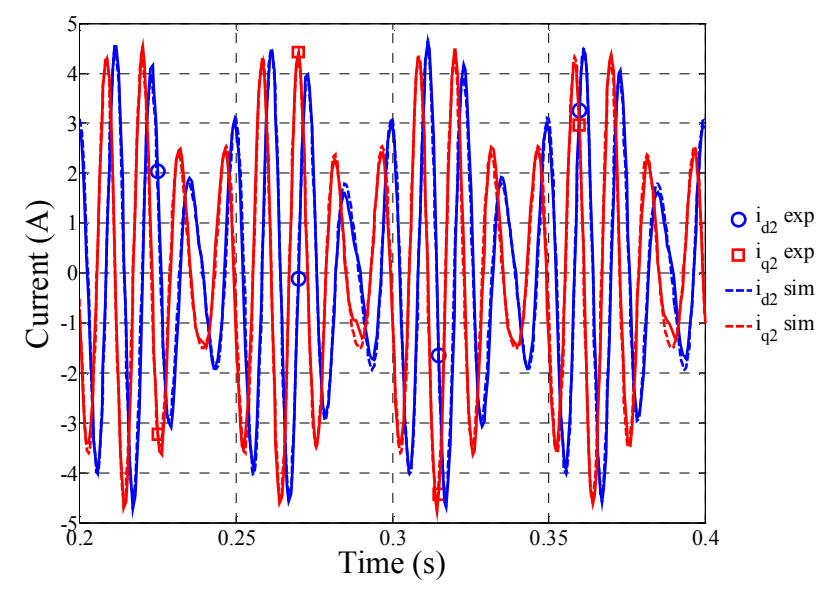

Fig. 9. Experimental and Simulated $M_{2} d q$ currents in the case of three open-circuited phases.

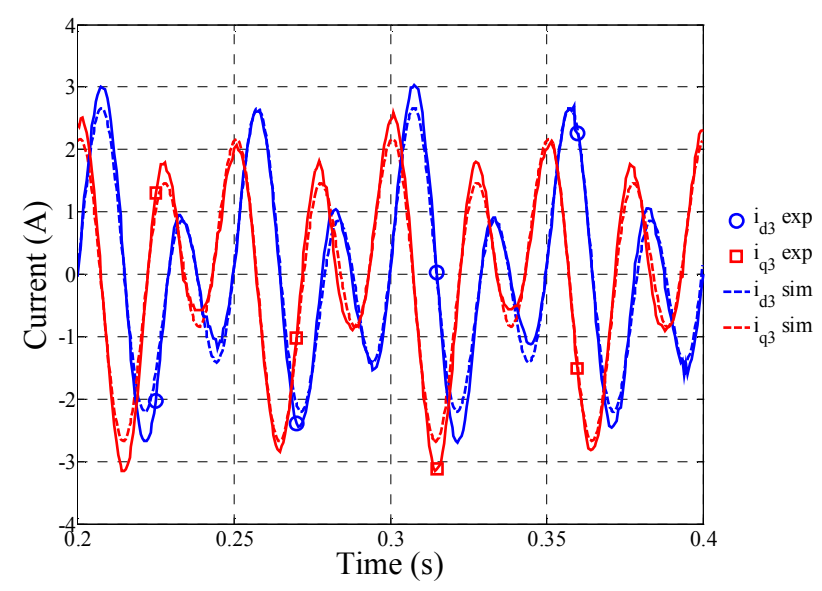

Fig. 10. Experimental and Simulated $M_{3} d q$ currents in the case of three open-circuited phases.

\section{CONCLUSION}

This paper provides an easy-to-implement way to model multi-phase drives in various configurations using a unique integral model. This opportunity makes it possible to rapidly analyze the effect of the total number of phases, of the topology of connection or of the type of fault on machine variables.

Used for numerical simulation, the connection resistances make the deduction of multiple $d q$ variables harmonic content possible, which is essential for advanced current controls.

Experimental measurements on a seven phase drive show the effectiveness of the proposed solution.

\section{REFERENCES}

[1] T.M. Jahns, "Improved reliability in solid state ac drives by means of multiple independent phase-drive units", IEEE Trans. on Industry Appl., vol. IA-16, pp. 321-331, May-June 1980.

[2] Y. Zhao and T. Lipo, "Space Vector PWM Control of Dual Three-Phase Induction Machine Using Space Vector Decomposition", IEEE Trans. on Industry Applications, vol. 31, no. 5, Sept./Oct. 1995 , pp. 1100-1109.

[3] H-M Ryu, J-W Kim and S-K Sul, "Synchronous Frame Current Control of Multi-Phase Synchronous Motor, Part I. Modeling and Current Control Based on Multiple d-q Spaces Concept Under Balanced Condition", Proc. of IEEE-IAS'04, Vol. 1, pp. 56-63, Seattle (USA), Oct. 2004.

[4] H. A. Toliyat, "Analysis and Simulation of Five-Phase VariableSpeed Induction Motor Drives under Asymmetrical Connections", IEEE Trans. on Power Electronics, Vol.13, No.4, pp.748-756, July 1998.

[5] H-M Ryu, J-H Kim and S-K Sul, "Synchronous Frame Current Control of Multi-Phase Synchronous Motor, Part II. Asymmetric Fault Condition due to Open Phases", Proc. of IEEE-IAS'04, Vol. 1, pp. 268-275, Seattle (USA), Oct. 2004.

[6] V. Pant, G.K. Singh and S.N. Singh, "Modelling of a Multi-phase Induction Machine under Fault Condition", Proc. of IEEE 1999 International Conference on Power Electronics and Drive Systems, PEDS'99, July 1999, Hong Kong.

[7] Dougal, R., Liu, S., Gao, L. and Blackwelder, M., "Virtual test bed for advanced power sources", Journal of Power Sources 110 (2): 285-294.

[8] Y. Crevits, X. Kestelyn, E. Semail, "Investigation on vector control of three-phase synchronous machines under supply fault condition", Power Electronics, Electrical Drives, Automation and Motion, 2006. SPEEDAM 2006. International Symposium on May, 23rd-26th, pp. 439-444, 2006.

[9] F. Locment, E. Semail and F. Piriou, "Design and Study of a Multi-phase Axial-flux machine", IEEE Trans. on Magnetics, vol. 42, no. 4, pp. 1427-1430, April 2006.

[10] Bennett J.W., Jack A.G., Mecrow B.C., Atkinson D.J., Sewell C., Mason G., "Fault-tolerant control architecture for an electrical actuator", 2004 35th Annual IEEE Power Electronics Specialists Conference, June 20-25, 2004, Aachen, Germany.

[11] E. Semail, X. Kestelyn, and A. Bouscayrol, "Right Harmonic Spectrum for the back-electromotive force of a n-phase synchronous motor", Proc. of IEEE-IAS'04, Vol. 1, pp.71-78, Seattle (USA), Oct. 2004.pp 1364-1371. 